\title{
An observational study to evaluate the Mukhyamantri Baal Hriday Upchaar Yojana (MBHUY) in a city of central India
}

\author{
Bansal SB ${ }^{1}$, Dixit $S^{2}$, Gupta $G^{3}$, Guleri $S^{4}$, Sabde $Y^{5}$, Saroshe $S^{6}$ \\ ${ }^{1}$ Dr S B Bansal*, Associate Professor, ${ }^{2}$ Dr Sanjay Dixit*, Professor and Head, ${ }^{3}$ Dr Girjesh Gupta*, PG Student, ${ }^{4}$ Dr Sunilkant \\ Guleri*, PG Student, ${ }^{5}$ Dr Yogesh Sabde, Professor of Community Medicine, R D Gardi Medical College, Ujjain, India, ${ }^{6}$ Dr \\ Satish Saroshe*, Assistant Professor. *All affiliated with Department of Community Medicine, M G M Medical College, \\ Indore, India
}

Address for correspondence: Dr Satish Saroshe, Email: drsatishsaroshe@gmail.com

\begin{abstract}
Introduction: Mukhyamantri Bal Hriday Upchar Yojna (MBHUY) is a Government scheme which was launched in the state of Madhya Pradesh (M.P) in 2011. Children suffering from congenital heart diseases have been identified and operated under Mukhyamantri Bal Hriday Upchar Yojna. The scheme has authorized 15 hospitals (10 in the state and 5 outside) for operative procedures. Present study was aimed to study the beneficiaries who have been operated and benefitted and to study the flow mechanism of grant provided under MBHUY and to identify the out of pocket expenses, if any. Methodology: Cross sectional study on 80 children using Pre designed, Semi Structured Questionnaire was used for data collection using Convenient Sampling Information about MBHUY. Conclusion: Majority of beneficiaries belonged to younger age groups (under five 76\%, infants $48 \%$ ) and their families represented all economic stata. Most common disease condition was VSD (30\%) followed by ASD (18\%). Anganwadi and health personnel were the main source of information and Chief Medical and Health Officer was the main procedural channel. No benificiery needed to go outside Indore for treatement. Benificiarries were allocated amount between 0.5 to 1.5 lacs in most of the cases. Time taken for approval of amount was 3 months and some benificieries needed to spend out of pocket in addition to support from of scheme. Conclusions: The implementation of the scheme was in helping the benificieries in better utilization of medical services. Important concerns were time taken for approval of fund and need to pay out of pocket that need to be addressed urgently.
\end{abstract}

Keywords: Mukhyamantri Baal Hriday Upchaar Yojana (MBHUY), Congenital Heart Disease, demand side interventions, access to health care

\section{Introduction}

\section{Burden of Congenital Heart Disease (CHD):}

Congenital Heart Disease (CHD) refers to structural and functional heart diseases which are present at birth. ${ }^{1-4}$ Some of these lesions may be discovered later. The reported incidence of the CHD is $8-10$ per thousand live births according to various studies from the different parts of world. Near $32-50 \%$ of these defects are critical requiring interventions in the first year of life. ${ }^{5,6,7,8}$ In India the incidence of CHD varies from as low as 2.25 to 5.20 per 1000 live births. Nearly, 1 lac 80 thousand children are born with heart defect each year in India. Of these nearly 60 thousand to 90 thousand suffer from critical cardiac lesion, requiring early intervention and

Manuscript received: $15^{\text {th }}$ Sep 2013

Reviewed: $16^{\text {th }}$ Oct 2013

Author Corrected; $29^{\text {th }}$ Oct 2013

Accepted for Publication: $30^{\text {th }}$ Nov 2013 treatment in India. Approximately $10 \%$ present infant mortality in India may be accounted by CHD alone. ${ }^{9}$ In the state of Madhya Pradesh (MP), on an average one child out of one thousand children has heart disease by birth.

Access to Paediatric Cardiac Care in India: There are no govt. policies for cardiac care in India except some subsidies from Govt. hospitals and voluntary organizations for open heart surgeries. There were no Paediatric Cardiac Care Programme in several states in the India and Heart diseases in the children are not identified as a health priority by the goverment in our country. In 2011 the estimated number of children with CHD in MP was 30 thousand, but only 10 to 15 thousand children had undergone any surgery. ${ }^{9}$ Lack of awareness, limited knowledge of natural history of CHD, expensive nature of Paediatric Cardiac Care, for an average Indian family are some of the reasons for poor access to pediatric 
cardiac care in poorer states like MP in India. Cost approximately 50-60 thousand in Govt. Hospitals. The cost may be 2-5 times in private and semi-private hospitals. $^{9}$

\section{Mukhyamantri Bal Hriday Upchar Yojna (MBHUY):}

On this background, Government of Madhya Pradesh (MP) introduced Mukhyamantri Bal Hriday Upchar Yojna (MBHUY) which is a state sponsored scheme, launched on 14 july 2011.1, 2, 3 Children suffering from congenital heart diseases have been identified and operated under Mukhyamantri Bal Hriday Upchar Yojna. The scheme authorized 10 hospitals in the state and 5 outside for operations. The diseases covered under MBHUY are ventricular septal defect, atrial septal defect, tetralogy of fallot, patent ductus arteriosis, pulmonary stenosis, coarctation of aorta and rheumatic heart disease. , $3,4,10,11,12^{2}$ Under the scheme, financial assistance upto maximum Rs. 1 lakh is provided to concerning government and recognised private hospitals for heart surgery of BPL(Below Poverty Line) children from 0 to 15 years of age, who suffer from heart disease. So far, 2602 children have been provided benefit of the scheme since its launch in year 2011 at a cost of over Rs. 9 crore. ${ }^{13,14}$ A provision of Rs. 15 crore has been made under Rajya Bimari Sahyta Nidhi (Provincial disease assistance fund). Under MBHUY the government provided the stipulated rates for the procedure, irrespective of the outcome. The stipulated rates are as follows; ASD (INR. 80,000) VSD (INR 90,000), TOF (INR 100,000), Valve Replacement (130,000), PDA/Surgical ligation (INR 25,000), Coarctation of aorta (INR 30,000) 13,14. However additional financial assistance for providing care to the affected child can be given by govt. agency through various policies and welfare funds.

\section{Process under MBHUY is as follows;}

1. The beneficiary goes to the hospital.

2. The patient is examined and disease is detected.

3. The amount required for the treatment of the detected disease is quoted.

4. The report is then sent to the chairman of committee.

5. Registration is done, the patient is sent for 2 nd opinion.

6. The final opinion sheet is then sent to the Civil surgeon.

7. Then finally it goes to CMHO Office where the final procedure takes place.

MBHUY is the first state sponsored financial assistance scheme for children suffering from congenital heart diseases. The scheme has been launced in 2011 and is benifitteing large number of benificierier with its financial provisions. At this juncture it is needed to evaluate the scheme so as to facilitate maximum advantages of the provisions under the scheme, Therefore the present study was carried out with the objectives to:-

1. study the profile of beneficiaries who have been benefitted under MBHUY.

2. study the role of different stakeholders in mechanism of grant provided under MBHUY.

3. quantify the expenses incurred for treatement under the scheme and identify any out of pocket expenses paid by the beneficiary under MBHUY.

4. give appropriate recommendations based on the findings of the present study.

\section{Material and Methods}

Type of study: Cross sectional study

Study area: The study was conducted in Indore division of MP. MP is large central state (area 308,252 sq kilometers) of India with a population of population 72 million [census 2011]. The infant mortality rate (IMR: 65 per 1,000 live births) in MP are amongst the highest in the country [Chandramouli C: Annual Health Survey Bulletin 2011-12]. Indore division is an administritave unit of MP state that cover 8 districts surrounding Indore district in the western part of MP. The total population covered by Indore division is 12543372 [census2011]

Study setting: The 15 hospitals authorized under the MBHUY scheme of State of Madhya Pradesh India.

Sample size: The list obtained was of 130 children out of which 80 were contacted.

Inclusion criteria: Children of age group 0-15 yrs who are amongst the beneficiaries of MBHUY living in any district of Indore division.

Exclusion criteria: Beneficiaries of MBHUY who do not live in Indore division, out of the list which was obtained from CMHO Office Indore

Study period: October 2012 - January 2013

Study tool: Pre designed, Semi Structured Questionnaire was used for data collection.

Sampling technique: Convenient Sampling

Data collection tool: A list of 130 beneficieries obtained from $\mathrm{CMHO}$ office Indore division. Their residencial addresses were recorded from the treating hospitals. A team of trained surveyors visited the families of the children at their residencial address to administer a pilottested, predesigned, semistructured proforma after their informed consent. Information about MBHUY was collected, to ask about age of the child, BPL status of the family (Criteria for BPL: Income below 26 Rupees per day - in rural areas, Below 32 Rupees per day - in urban areas According to planning commission of India), source of information about the scheme, source of application for the scheme, the length of hospital stay (time between pre- 
operative procedures till discharge from hospital) and any amount spent out of pocket. The list obtained from $\mathrm{CMHO}$ office Indore provided the type of disease (diagnosis) of the child and the amount allocated under the scheme.
Analysis: The data were compiled in Epidata version 3.1 and analysed using Epi analysis version 3.1. Frequency distribution tables and charts were prepared for the comparison of study veriables.

\section{Results}

The list obtained was of 130 children out of which 80 could be contacted at the home.

Table 1 shows the age distribution of the beneficiaies. $76 \%$ of the beneficiaries belong to $0-5$ year age group; Most of the beneficiaries (48\%) are of the infant (0-1 year) age group. Table 2 shows the BPL status of the families of the beneficiaries. Though only 32 (40\%) families declared their status as BPL another 32 (40\%) did not reveal their BPL status.

Table 3 shows the top three types of disease among which the commomnest was VSD (30\%) followse by ASD (18\%) The other diseases included TOF, Coarctation of aorta, Transposition of great vessels, etc.

Graph 1 shows the sources of information for the families. Out of 80 beneficiaries $40(50 \%)$ got information from Anganwadi and health personnel (Graph 1) while 20 beneficiaries (25\%) got information from print media or other benificiaries.

Table 4 shows the application channel for the beneficiaries. Graph 2 shows the source of fund allotment. Majority (70\%) of the beneficiaries applied through Chief Medical and Health Officer office and also majority were (62\%) were allocated funds from CMHO office. Irrespective of the the source, majority (90\%) of the benificieries reported that it took around 3 months for approval of application form and allocation of funds to the hospital.

Graph 3 shows the hospitals in which the patients were operated. Most of the surgeries were performed by Bhandari hospital (58\%), CHL Apollo (32\%) hospital. Table 5 shows the amount allocated to the hospital in which the operation of the beneficiary was performed. Most of the benificieries (94\%) were allocated amounts between 50 thousand to 1.5 lakh rupees.

Amount of more than 1.5 lac rupees was provided to only 2 benificieries which was considered under special circumstances. Graph 4 shows the amount out of pocket expenses beneficiaries though majority did not pay out of pocket $8 \%$ had paid $>$ INR20,000.

Table 6 shows the total length of stay for the beneficiaries majority of the benificieries (94\%) were discharged within 10 days

Table No 1: Age distribution of the beneficiaries of Mukhyamatri Bal Hriday Upchar Yojna

\begin{tabular}{|c|c|c|}
\hline Age (Years) & Number & Percentage \\
\hline $0-1$ & 39 & $48 \%$ \\
\hline $2-5$ & 22 & $28 \%$ \\
\hline $6-10$ & 5 & $8 \%$ \\
\hline $11-15$ & 14 & $16 \%$ \\
\hline TOTAL & 80 & 100 \\
\hline
\end{tabular}

Table No 2: Economic status of beneficiaries of Mukhyamatri Bal Hriday Upchar Yojna

\begin{tabular}{|c|c|c|}
\hline Beneficiary & Number & Percentage \\
\hline BPL $^{*}$ & 32 & 40 \\
\hline APL & 16 & 20 \\
\hline OTHER & 32 & 40 \\
\hline TOTAL & 80 & 100 \\
\hline
\end{tabular}


*Criteria for BPL: Income below 26 Rupees per day - in rural areas, Below 32 Rupees per day - in urban areas (According to planning commission of India).

Table No 3: Types of Heart Diseasefrom In list from CMHO Indore

\begin{tabular}{|c|c|c|}
\hline Diseases & Number & Percentage \\
\hline VSD & 24 & 30 \\
\hline ASD & 15 & 18 \\
\hline TOF & 1 & 2 \\
\hline Others* & 40 & 50 \\
\hline TOTAL & 80 & 100 \\
\hline
\end{tabular}

*Others - Coarctation of aorta, Transposition of great v essels, etc.; Out of 80 beneficiaries 30\% suffer from VSD

Table No 5: Amount allocated to the hospital in which the operation of the beneficiary was performed

\begin{tabular}{|c|c|c|}
\hline Amount (Rs.) & Number & Percentage \% \\
\hline$<50,000$ & 3 & 4 \\
\hline $50,000-1 \mathrm{Lac}$ & 52 & 64 \\
\hline $1-1.50 \mathrm{Lac}$ & 24 & 30 \\
\hline$>1.50 *$ lac & 1 & 2 \\
\hline TOTAL & 80 & 100 \\
\hline
\end{tabular}

Table No 4: Application forms to avail the benefits of the scheme were obtained from either of the following

\begin{tabular}{|c|c|c|}
\hline $\begin{array}{c}\text { Source Of } \\
\text { Application }\end{array}$ & Number & Percentage \\
\hline From CMHO & 56 & 70 \\
\hline $\begin{array}{c}\text { From Mahila \& } \\
\text { Kendra }\end{array}$ & 15 & 18 \\
\hline From PHC & 3 & 4 \\
\hline From & 6 & 8 \\
Collectorate & & \\
\hline TOTAL & 80 & 100 \\
\hline
\end{tabular}

Table No 6: Total Duration of stay of beneficiary in Hospital

\begin{tabular}{|c|c|c|}
\hline Days & Number & Percentage \\
\hline$<5$ days & 58 & 72 \\
\hline $5-10$ days & 18 & 22 \\
\hline $10-15$ days & 1 & 2 \\
\hline$>15$ days & 3 & 4 \\
\hline TOTAL & 80 & 100 \\
\hline
\end{tabular}

*Amount of more than 1.50 lac Rupees was provided only under special circumstances. (The upper limit allowed by the government is $1.5 \mathrm{lac})$

The amount sanctioned was according to the disease, equipment required \& hospital \& doctors' fees. 
Graph No 1: Allocation of funds to

the beneficiaries under MBHUY

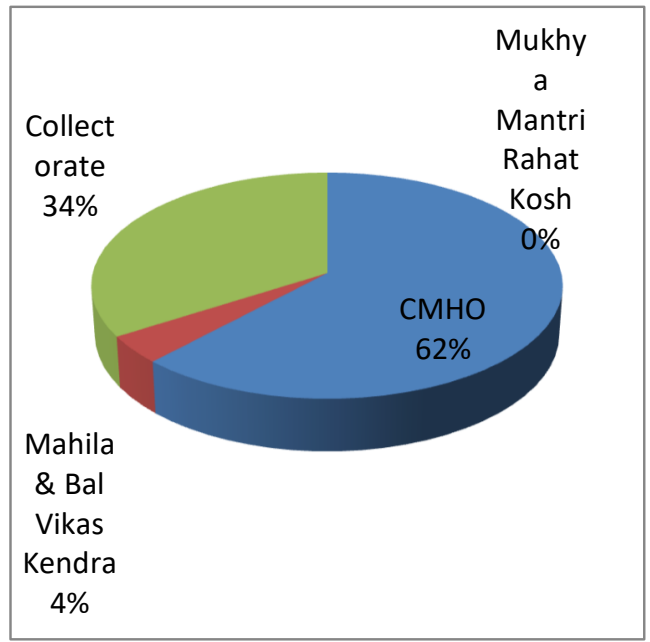

$62 \%$ beneficiaries were provided funds

from the $\mathrm{CMHO}$ office Indore .

\section{Research Article}

Graph No 2: Source of information

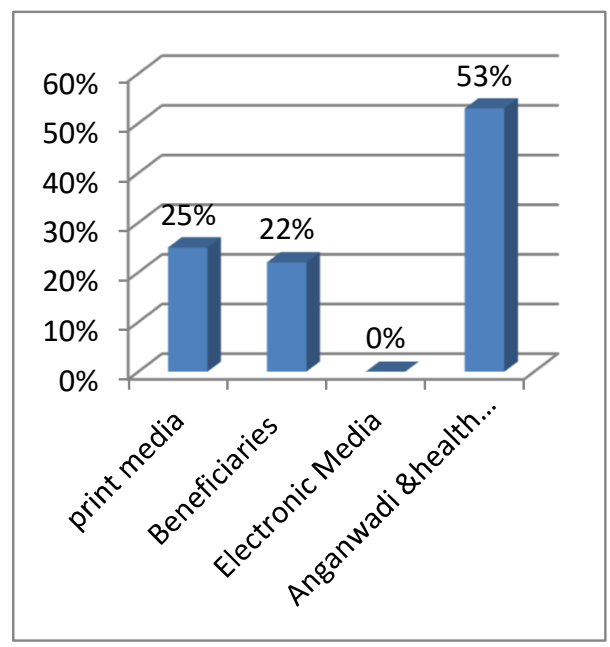

\section{Graph No 3: Hospitals in which the patient} were operated

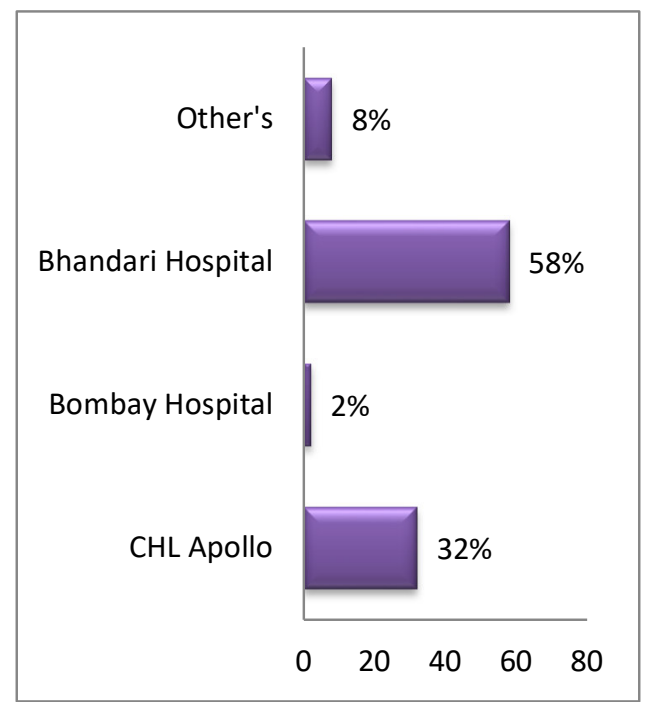

Graph No 4: Did beneficiary need to pay any amount from his own pocket

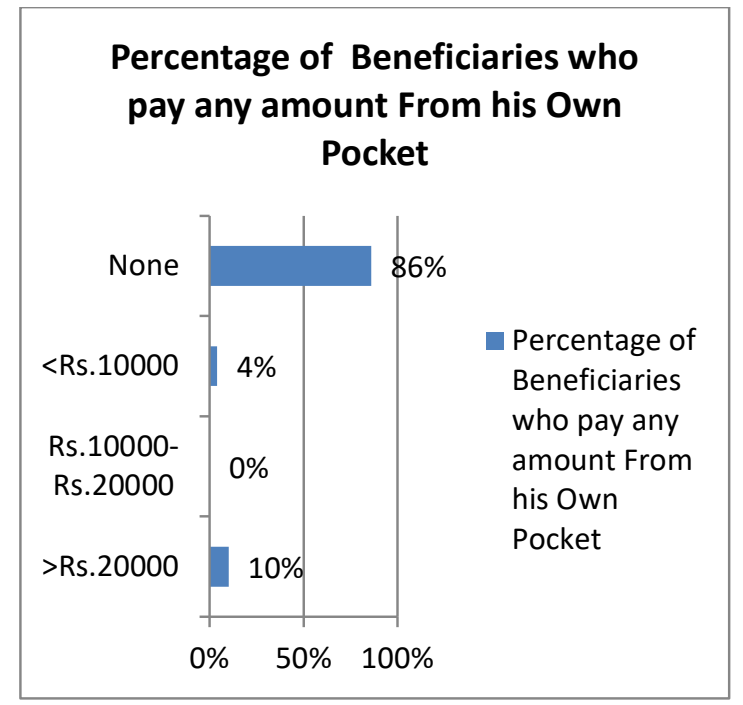

*(Others - Gokuldas Hospital, CHL Ujjain, AIIMS New Delhi, Vishesh Hospital etc)

\section{Discussion}

Since there was no study available, at the time of initiation of the study the authors were not able to find any previous study to evaluate MBHUY, hence it was difficult to evaluate and compare the findings with this study. Therefore in this discussion we have compared our study findings with the standard procedures of MBHUY.

Profile of benificieries: The age group included in MBHUY was 0-15 years with compulsory Birth 
certificate. In our study $76 \%$ of the beneficiaries belong to 0-5 year age group; among them two third were infants (0-1 year) age group. This was because of early and severe manifestation of most of the CHDs that need timely intervention for better outcomes [ref natural h/o CHD].

To give priority is given to children of poor families who are affected due to heart disease; initially the MBHUY was only for Below Poverty Line (BPL) category. However, later it was open for all. In our study $40 \%$ families were BPL while the remaining were not.

This relaxation of the BPL norm has benifitted additional $60 \%$ children from non-BPL families who were also in need of financial assistance owing to the high costs of cardiac surgeries. Most common congenital heart disease operated was VSD (30\%) followed by ASD (18\%). The other diseases included TOF, Coarctation of aorta, Transposition of great vessels, etc. This was because VSD is the commonest presentation of treatable CHD in

India. ${ }^{16}$ most of the benificieries did not require very long length of stay indicating favourable treatement outcomes.

\section{Main service providers in Scheme (Stakeholders):}

Source of information: Like most of the other government health care schemes Anganwadi and health personnel (Graph 1) were the main source of information about MBHUY.

Given the poor contribution of electronic and print media there is a need to harness these efficient tools for maximum coverage of the scheme. ${ }^{15}$ For this venture pediatrician, pediatric cardiologist, voluntary organization, industry and media need to initaite collaborative efforts with policy makers.

Procedural channels: Initially Civil Surgeon was the nodal officer later a committee was formed which comprises of the Dean and the Joint Director, Health. In our study majority $(70 \%)$ of the beneficiaries applied for the scheme hrough Chief Medical and Health Officer and got their funds allocated thrugh the same.

Treating hospitals: At state level the scheme has authorized 10 hospitals in the state and 5 outside for operations. The hospitals authorized in the state include Gandhi Medical College Hamidia hospital Bhopal, Bhandari Hospital and Research Centre Indore, Bhopal Memorial Hospital And Research Centre Bhopal, CHL Hospital Indore, CHL Medical Centre Ujjain, Chirayu
Cardiac Centre Bhopal, Bombay Hospital Indore, Gokuldas Heart Hospital Indore, Vishesh Hospital Indore. Authorized hospitals outside the state are - All India Instituute of Medical Sciences (AIIMS) New Delhi, All India Child Heart Institute Trivandrum, Cherian Madras Mission hospital Chennai, Narayana Hridayalay Mangalore, Escort Heart Institute New Delhi. ${ }^{1-4}$ Our data shows that majority of the surgeries performed in Indore division were performed by Bhandari hospital (58\%), CHL Apollo (32\%) hospital which were located in Indore itself and no benificiery needed to travel out of the state for treatement.

Procedural delay: An important finding here was irrespective of the channel of application or treating hospital It took around 3 months for approval of application form and allocation of funds to the hospital. This duration is too long given the fact that almost every second beneficiary $(48 \%)$ was an infant.

Financial support in the scheme: Table 5 shows the amount allocated to the hospital in which the operation of the beneficiary was performed. Most of the benificieries (94\%) were allocated amounts between 50 thousand to 1.5 lakh rupees. Amount of more than 1.5 lac rupees was provided to only 2 benificieries which was considered under special circumstances.

Graph 4 shows the amount out of pocket expenses beneficiaries did not had to pay for the procedures. Most of the benificieries were relieved of their costly expenses of cardiac surgery for following reasons. The government provided the stipulated rates for the procedure, irrespective of the outcome though all the hospitals were liable for annual quality check and any center found to have above average morbidity and mortality, risk barring them from the schemes' list of hospitals.

The scheme covered all procedures included: all relevant investigations, hospital stay, food and drugs and atleast one post-operative revisit with any relevant investigation within first 3 months of surgery. The hospital did not charge anything extra from the patient. Any additional cost arising due to untoward complications during procedures were borne by the hospital.

All patients were subjected to random scrutiny by a team of government doctors/specialist who randomly assessed if the surgery carried out was as per the grant received. Hospital not complying with the above were supposed to black listed for a period of 3 years. It is ensured that the child patient gets medicine post operation as well; assistance amount can also be sought from donor besides Rajya Bimari Sahayta and chief minister discretionary fund. ${ }^{1-4}$ Compliance report of all the procedures with the discharge summary was filed by the respective hospitals

Available online at: www.ijmrr.in 13 | P a g e 
within 3 months of the procedure performed else, no more patients were referred to that hospital. Any hospital demanding extra money beyond the agreed upon rate were black listed from the scheme.

\section{Methodological considerations}

- Short duration of study (there was less time to conduct the study on large scale)

- Financial constraint (As the procedure was long one and study duration was less and due to the financial constraint, it was not feasible to conduct the study on large scale.)

- Inadequate availability of human resources

- Study was conducted on a very small scale; a larger scale study should be conducted for better results.

\section{Conclusion}

Mukhyamantri Bal Hirday Upchar Yojna was started on 14 July 2011. Families benefited by MBHUY belong to almost all socio-economic status. And the benificieries were mainly under five aage group.

The important stakeholders were Anganwadie and health workers, CMHO office and two hospitals in Indore indicating that the Indore division was technically self sufficient to run the scheme.

However increasing community awareness through electronic media can be beneficial. Most of the benificieries were allocated amount between 0.5 to 1.5 lack based on the disease condition and their outcomes as indeated by length of stay were acceptable.

Most important concerns about the scheme were 1)The time taken for transfer of fund to the hospital which was around 3 months.

2) Though less in proportion (11\%) the benificieries needed to pay out of pocket amount as high as INR 20,000 in $8 \%$. Both these concerns can adversely influence the utilization and potential clinical benefits of the scheme.

The following recommendations were put forward:-

- Govt. should advertise on a larger scale through print and electronic media for better implementation of MBHUY.

- The govt. should make the formal procedures fast and easy to release the fund as early as possible.
- Limit of the funds in MBHUY is upto 1.5 lac rupees but in some cases it is not sufficient to treat the disease. Govt. should provide extra funds according to patient's need.

- Development of swift mechanism for fast disbursement of monitory benefit under MBHUY.

Funding: Nil

Conflict of interest: Nil

Permission from IRB: Yes

\section{References}

1. Available on http://www.theindiapost.com/nation/ madhya-pardesh/mukhyamantri-bal-hirday-upcharyojana-launched-today/ accessed on 23-10-2013

2. Available on http://www.mpnewsonline.com/HView News.aspx? NewsID=157 accessed on 23-10-2013

3. Available on http://news.webindia123.com/news/ articles/India/20110612/1769868.html accessed on 23-102013

4. Available on http://www.bharateseva.com/bharat/ 1_news_detail.asp?id=4147 accessed on 23-10-2013

5. Khalil A, Aggerwal R, Thirupurum S, Arora R. Incidence of congenital heart disease among hospital born live births in India. Indian Pediatr 1994; 31: 519-527.

6. Smitha R, Karat SC, Narayanappa D, Krishnamurthy B, Prasanth SN, Ramachandra NB. Prevalence of congenital heart diseases in Mysore. Indian J Hum Genet 2006; 12 : $11-16$

7. Kapoor R, Gupta S. Prevalence of congenital heart diseases, Kanpur India. Indian Pediatr 2008; 45: 309-311.

8. Chadha SL, Singh N, Shukla DK. Epidemiological study of congenital heart disease. Indian J Pediatrics 2001; 68: 507-510.

9. Anita saxsena Congenital heart disease in india: a status report Indian journal of pediatrics vol. 2 july 2005 .

10. Available on http://www.mpinfo.org/MPinfoStatic/ english/articles/2013/100813Lekh22.asp accessed on 2310-2013

11. Available on http://dailybreaking.com/archives.asp? News ID $=626 \&$ PageID $=3$ accessed on 23-10-2013

12. Available on http://www.centralchronicle.com/ mukhyamantri-bal-hriday-upchar-yojna-to-benefit-twothousand-children.html accessed on 23-1-2013 
13. Available on http://www.mpnewsflash.com/go.php? show $=$ newsdetails $\&$ title $=$ Top $\% 20$ Stories $\&$ id $=825$ accessed on 23-1-2013

14. "Report of Mukhyamantri Bal Hriday Upchaar Yojana” CMHO- Chief Medical \& Health Officer, Indore, 2012-13
15. K. Park - Textbook of Preventive and Social Medicine - 21st edition - 2011 - Page No. 339 Publisher M/s Banarsidas Bhanot - ISBN no. 9788190607995

16. Available on http://www.apollolife.com/HealthTopics/ ChildrensHealth/CongenitalHeartDiseaseinIndia.aspx accessed on 23-10-2013

\section{How to cite this article?}

Bansal SB, Dixit S, Gupta G, Guleri S, Sabde Y, Saroshe S. An observational study to evaluate the Mukhyamantri Baal Hriday Upchaar Yojana (MBHUY) in a city of central India. Int J Med Res Rev 2014;2(1):8-15,10.17511/ijmrr.2014.i01.03 